\title{
CHANGES IN THE ARMY NURSE CORPS
}

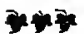

\author{
CHANGES IN THE ARMY NURSE CORPS RECORDED IN THE \\ SURGEON-GENERAL'S OFFICE FOR THE MONTH ENDING \\ DECEMBER I2, I903.
}

Chamberlin, Anna B., now on duty at the General Hospital, Presidio, San Francisco, Cal., under orders to sail for the Philippines on January 1, 1904, for duty in that division.

Fall, Mrs. Mary B., transferred from the General Hospital, Presidio, San Francisco, Cal., to duty at the General Hospital, Fort Bayard, N. M.

Hally, Mary C., transferred from the General Hospital, Presidio, San Franeiseo, Cal., to duty in the Philippines. Sailed on the transport Logan December $1,1903$.

Hunt, Helen Grant, on duty at the General Hospital, Presidio, San Francisco, Cal., under orders to sail for the Philippines on January 1, 1904, for duty in that division.

Mann, Mrs. Emilyn P., arrived in New York on the Sumner from the Philippines via the Suez; on leave of absence; after leave will be assigned to duty at the General Hospital, Presidio, San Franciseo, Cal.

Smith, Stella, formerly on duty at the General Hospital, Fort Bayard, N. M., discharged.

Wilson, Sibbie, transferred from the General Hospital, Presidio, San Francisco, Cal., to duty at the General Hospital, Fort Bayard, N. M.

Winslow, Minnie A., reappointed and assigned to duty at the General Hospital, Presidio, San Franciseo, Cal.

\section{NEW ARMY REGULATIONS}

UNDER date of November 16, 1903, the War Department has issued new orders governing the Nurse Corps, with some changes that are of interest. We publish the section in which the most important change has been made:

“ APPOINTMENT AND DISCHARGE.

"4. The appointments and discharges of nurses shall be made by the Surgeon-General with the approval of the Secretary of War.

“( $a$ ) Nurses may be discharged from the service (1) at any time when their services are no longer needed, (2) on account of illness, and (3) for misconduct. Recommendation for the discharge of a nurse on account of misconduct will be submitted to the Surgeon-General with a report of the facts after a careful investigation, of which she shall have due notice and at which she shall have a fair opportunity to be heard in her own defence, and when so diseharged the endorsement on the appointment indicating discharge, as provided in paragraph $4(d)$ of this order, will state "for misconduct" and the word "honorably" will be omitted.

" (b) A nurse requesting discharge before the expiration of the three years 
stipulated in her appointment will ordinarily be required to refund to the Government the amount of her transportation and necessary expenses incurred in obeying her first order. The amount of such reimbursement will be fixed by the Quartermaster-General and payment in accordance therewith will be made to the nearest quartermaster. Requests for dischar: - must be made to the Surgeon-General and the reasons therefor must be given, supported by a full statement of the facts in the case. An official copy of the order directing her first journey at Government expense must be inclosed. A nurse discharged under this paragraph will not be given orders to proceed to her home.

"The Surgeon-General may at his discretion waive the provisions of this paragraph.

“ (o) The following form will be used in making appointments of nurses to the Army Nurse Corps:

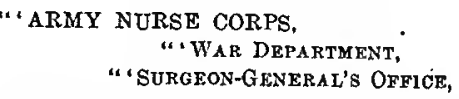

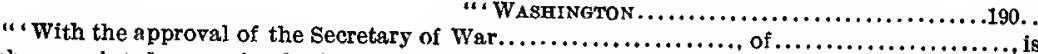
hereby appointed nurse in the Nurse Corps (female) for (at least) three years, unless snoner discharged, to date from $\ldots \ldots \ldots \ldots \ldots \ldots \ldots \ldots \ldots \ldots, 190 . \ldots$, and will enter upon her duties after taking the oath prescribed by section 1757 of the Revised Statutes of the United States.

"'Surgeon-General, U.S. Army.'

“(d) Upon honorable discharge from service the following indorsement will be placed on the appointment of the nurse:

$$
\text { "c }
$$
190.

"'With the approval of the Secretary of War, honorably discharged from the Army Nurse Corps

"The authority directing her discharge will be quoted."

It is the desire of the Surgeon-General to have the rules governing the Nurse Corps conform as closely as possible to the rules governing the other branches of the service, and during the five years' existence of the Army Nurse Corps there have been many instances where it was felt that the right given in the regulations to request discharge reacted disadvantageously to the best interests of the service.

Note that Section $b$ of this same paragraph is entirely new. That this may work no hardship upon those who are forced to request discharge, the closing sentence has been added, leaving it discretionary with the Surgeon-General to enforce or not the penalties of the paragraph.

In the form of the appointment the words "at least" have been inserted before "three years." This was done to obviate the necessity of reappointing nurses at the termination of three years for another term of three years. It was felt that having given meritorious service for that length of time it was desirable to leave it an open question with them as to how much longer they would serve, not forcing them to accept another appointment for another term of three years. Many might feel disinclined to commit themselves to this who would, if the question were not brought to a decision, continue to serve indefinitely. 